This page intentionally left blank 


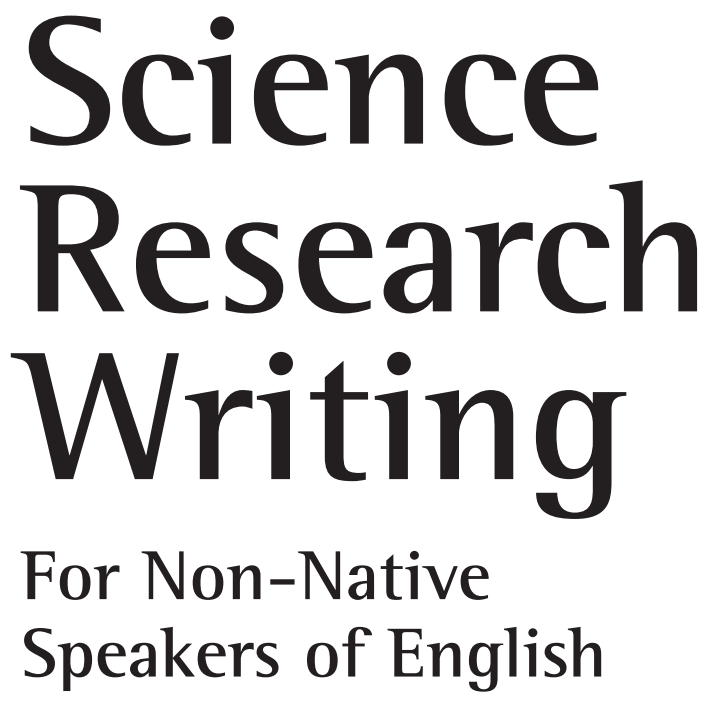

\section{Hilary Glasman-Deal} Imperial College London, UK 
Published by

Imperial College Press

57 Shelton Street

Covent Garden

London WC2H 9HE

\section{Distributed by}

World Scientific Publishing Co. Pte. Ltd.

5 Toh Tuck Link, Singapore 596224

USA office: 27 Warren Street, Suite 401-402, Hackensack, NJ 07601

UK office: 57 Shelton Street, Covent Garden, London WC2H 9HE

\section{Library of Congress Cataloging-in-Publication Data \\ Glasman-Deal, Hilary. \\ Science research writing for non-native speakers of English / by Hilary Glasman-Deal. p. cm. \\ Includes bibliographical references. \\ ISBN 978-1-84816-309-6 (alk. paper) -- ISBN 978-1-84816-310-2 (pbk : alk. paper) \\ 1. English language--Technical English--Handbooks, manuals, etc. 2. Technical writing-- Handbooks, manuals, etc. 3. English language--Textbooks for foreign speakers. I. Title. PE1475.G57 2009 $808^{\prime} .0665--\mathrm{dc} 22$}

2009043016

\section{British Library Cataloguing-in-Publication Data}

A catalogue record for this book is available from the British Library.

Copyright (C) 2010 by Imperial College Press

All rights reserved. This book, or parts thereof, may not be reproduced in any form or by any means, electronic or mechanical, including photocopying, recording or any information storage and retrieval system now known or to be invented, without written permission from the Publisher.

For photocopying of material in this volume, please pay a copying fee through the Copyright Clearance Center, Inc., 222 Rosewood Drive, Danvers, MA 01923, USA. In this case permission to photocopy is not required from the publisher.

Printed in Singapore. 


\section{Introduction: How to Use This Book}

Things should be made as simple as possible, but not any simpler.

- Albert Einstein

\section{Who is this book for?}

This book is designed to help non-native speakers of English write science research papers for publication in English. However, it can also be used as a guide for native English speakers who would like support with their science writing, and by science students who need to write a Master's dissertation or $\mathrm{PhD}$ thesis. It is a practical, rather than a theoretical book, and is intended as a fast do-it-yourself manual for researchers and scientists.

The book is aimed at those whose English language ability is at intermediate level or above. If you have taken an IELTS test, this is equivalent to a score of above 6.0; if you have taken a TOEFL test then this is approximately equivalent to a score above 550 (paper-based test) or 91 (iBT). However, if you have managed to read this far without using a dictionary, you will be able to use this book, even if you don't understand every word.

\section{Why do I need it?}

The goal of scientific research is publication, but good scientists are not always good writers and even native speakers of English sometimes have difficulty when they write up their research. The aim of this book is to give you the information, vocabulary and skills you need quickly and easily so that you can write confidently using the style and structure you see in the journals you read. 
As a science researcher, you are able to read and understand complex, high-level material in your field. However, you may find it difficult to produce written English which is at the same level as your reading. You may feel that your English writing does not represent the content of your work effectively or accurately. The aim of this book is to enable you to use your reading ability and the material you read to develop the writing skills your work requires.

Developing the skills to write up your own research is the only way to join the international science community. If you depend on English speakers to translate your writing, their translation may not represent exactly what you intended. If you depend on proofreaders to correct your English they may not notice some errors, because a sentence which is grammatically correct is still 'wrong' if it does not mean what you intended. Also, a proofreader may not check whether your writing fits the conventional 'science research' patterns. For example, you may have forgotten to justify your choice of method or explain how your results relate to your original question, and this could mean that an editor of a science journal rejects your paper as unprofessional.

Writing and publishing a research paper is the best way to get your career off the ground. If you can turn your thesis or research project into a useful paper, your CV (Curriculum Vitae) will immediately look more professional and will be more competitive internationally. You may feel that you don't have the time to improve your English, but you already know most of what you need from the reading you have done over the years. In order to write up your research for publication you don't need to learn much more English than you already know. Science writing is much easier than it looks.

Most science research is written according to a fairly conventional structure: first the title, then the abstract, followed by an introduction, after which there is a central section which describes what was done and what was found and then a discussion and/or conclusion. At the end of the paper or research article, acknowledgements and references are added. This means that the structure of a research article will be quite similar for all writers.

Because science writing is so conventional, the amount of grammar and vocabulary you need to learn is quite small. For example, the nontechnical vocabulary used in scientific writing consists of a limited set of 
words such as attempt, conduct, interpret, evaluate, determine, implement, formulate, classify, correlate, enhance, which are used as a kind of 'code'. All the vocabulary you need to get started (apart from the specialised vocabulary of your field) is in this book.

\section{What will this book teach me?}

The book will show you how to discover the conventions of structure, organisation, grammar and vocabulary in science writing in your field and will provide you with the tools to write in a similar way and at a similar level. It will teach you how to turn your research into a paper that can be submitted to a professional journal. You will also be able to use most of the information in the book and all of the language and vocabulary if you are writing a thesis in English.

I have been teaching English for Academic Purposes to science students for over 30 years. For the past 15 years I have been teaching research writing in the English Language Support Programme at Imperial College, London, where I also work closely with individual research students and staff who are writing a paper or thesis. This book is based on the most useful thing I have learned: when your language skills are not perfect, organising your information in a conventional way and using conventional language are very important. If you write according to a conventional model, the reader knows what you are trying to do because the model you are following is familiar, and language errors are therefore less significant. A researcher who begins by writing according to a simple and conventional model will soon develop higher level skills for writing independently and professionally. The opposite is also true: researchers who do not begin by writing according to a conventional model are less likely to develop these skills.

\section{How does the book work?}

The strategy in this book can be summed up as follows: carefully examine good examples of the kind of writing you would like to produce, identify and master the structure, grammar and vocabulary you see in these examples and then apply them in your own writing.

The book is divided into five units, each dealing with one section of a research article. Unit 1 deals with the Introduction, Unit 2 the Methodology, Unit 3 the Results, Unit 4 the Discussion or Conclusion and Unit 5 the 
Abstract and Title. Since the aim of this book is to enable you to write in a conventional way, each unit is designed to help you discover what the conventional model of that section of a research article looks like. In each unit you will also be given support on the grammar and writing skills needed to write that section of the research article and you will be guided towards the appropriate vocabulary.

Each unit is similar. The unit on Introductions, for example, begins by looking at a sample research article Introduction similar to those in science journals, then there is a Grammar and Writing Skills section designed to respond to frequently asked questions. Because you are probably working hard on your research and don't have time to do much grammar work, there are very few grammar exercises in the Grammar and Writing Skills sections. In any case, getting the answer right in a grammar exercise doesn't automatically mean you will produce the correct grammar when you write about complex topics. Answering correctly can give you a false sense of confidence and security.

After the Grammar and Writing Skills section you will create a model or template for writing Introductions using the sample Introduction, and this is followed by a detailed Key providing model descriptors, discussion and answers to questions. The unit includes extracts from real Introductions so that you can test the model and see how it works in the 'real world'. These extracts are then used to find the vocabulary which will help you operate the model successfully. This is followed by a complete list of useful vocabulary together with examples of how the words and phrases are used.

At this stage, you will have a robust model of an Introduction, a grammar guide to deal with possible problems and a list of useful vocabulary to make the model work. Towards the end of the unit, you will be ready to test what you have learned by writing an Introduction. If you have done the tasks, you should be able to put the model, the grammar/writing skills and the vocabulary together, and a perfect Introduction will write itself almost automatically! So at the end of the unit on Introductions, you will try out what you have learned: you will write an Introduction using the model and the vocabulary list and then compare it with a sample answer in the Key.

This pattern is repeated in the rest of the units. Ideally, you should work through the book and do each task. If you read the book without completing the tasks you will have an intellectual understanding of what to do but you may find it harder to put it into practice. 
Do I need any other material or books?

No, but before you begin, you should collect three or four recent research papers in your field from the journals you usually read and photocopy them. You will use these as target articles to help you adapt what you learn here to your own work, and you will refer to them while reading this book to see how the things you are learning are done in your research field. Don't use chapters from books as target articles; they are not written according to the same conventional structure as research papers and so will not help you discover how a research paper or thesis in your field is written.

Your target research articles should:

- be written by a researcher/research team based at an English-speaking institution, ideally a native speaker of English.

- be reasonably short (less than $15 \mathrm{~A} 4$ sides including graphs and tables).

- deal with subject matter which is as close as possible to your own topic and the kind of research you are doing.

- have clearly defined Introduction, Methodology, Results and Discussion/ Conclusion sections. It will help you if these are subtitled so that you can locate them easily. Note that the subtitles may vary in different fields and even in different journals in each field; for example the Methodology can be called 'Procedure,' 'Materials and Methods', 'Experimental' or some other variation. 
This page intentionally left blank 


\section{Contents}

Unit 1: How to Write an Introduction

1.1 Structure

1.2 Grammar and Writing Skills

1.2.1 Tense pairs

1.2.2 Signalling language

1.2.3 Passive/Active

$\begin{array}{ll}1.3 \text { Writing Task: Build a Model } & 15\end{array}$

$\begin{array}{ll}\text { 1.3.1 Building a model } & 15\end{array}$

$\begin{array}{ll}1.3 .2 \mathrm{Key} & 17\end{array}$

1.3.3 The model 24

1.3.4 Testing the Model 25

1.4 Vocabulary $\quad 32$

1.4.1 Vocabulary for the Introduction $\quad 34$

1.5 Writing an Introduction 41

1.5.1 Write an Introduction 41

$\begin{array}{lll}1.5 .2 \mathrm{Key} & 42\end{array}$

Unit 2: Writing about Methodology

2.1 Structure 44

2.2 Grammar and Writing Skills $\quad 46$

2.2.1 Passives and tense pairs 47

2.2.2 Use of 'a' and 'the' $\quad 50$

2.2.3 Adverbs and adverb location 56

2.3 Writing Task: Build a Model 57

2.3.1 Building a model $\quad 57$

$\begin{array}{ll}2.3 .2 \text { Key } & 59\end{array}$ 
2.3.3 The model 66

2.3.4 Testing the model $\quad 67$

$\begin{array}{ll}2.4 \text { Vocabulary } & 75\end{array}$

$\begin{array}{ll}2.4 .1 \text { Vocabulary task } & 76\end{array}$

2.4.2 Vocabulary for the Methodology section $\quad 77$

2.5 Writing a Methodology Section $\quad 88$

2.5.1 Write a Methodology section $\quad 88$

$\begin{array}{ll}2.5 .2 \mathrm{Key} & 90\end{array}$

Unit 3: Writing about Results

$\begin{array}{lll}3.1 \text { Structure } & 91\end{array}$

3.2 Grammar and Writing Skills 94

$\begin{array}{ll}3.2 .1 \text { Sequence } & 94\end{array}$

$\begin{array}{lr}3.2 .2 \text { Frequency } & 99\end{array}$

$\begin{array}{ll}3.2 .3 \text { Quantity } & 102\end{array}$

3.2.4 Causality 108

3.3 Writing Task: Build a Model 111

$\begin{array}{ll}\text { 3.3.1 Building a model } & 111\end{array}$

$\begin{array}{ll}\text { 3.3.2 Key } & 113\end{array}$

$\begin{array}{ll}\text { 3.3.3 The model } & 122\end{array}$

3.3.4 Testing the model 124

$\begin{array}{ll}3.4 \text { Vocabulary } & 135\end{array}$

3.4.1 Vocabulary task 136

3.4.2 Vocabulary for the Results section 137

3.5 Writing a Results Section 149

3.5.1 Write a Results section $\quad 150$

$\begin{array}{ll}3.5 .2 \mathrm{Key} & 151\end{array}$

Unit 4: Writing the Discussion/Conclusion

$\begin{array}{lll}4.1 \text { Structure } & 154\end{array}$

4.2 Grammar and Writing Skills 158

4.3 Writing Task: Build a Model 167

$\begin{array}{ll}\text { 4.3.1 Building a model } & 167\end{array}$

$\begin{array}{ll}4.3 .2 \text { Key } & 170\end{array}$

4.3.3 The model 179

$\begin{array}{ll}\text { 4.3.4 Testing the model } & 180\end{array}$ 
4.4 Vocabulary

$\begin{array}{ll}\text { 4.4.1 Vocabulary task } & 187\end{array}$

4.4.2 Vocabulary for the Discussion/Conclusion 187

4.5 Writing a Discussion/Conclusion

4.5.1 Write a Discussion/Conclusion

Unit 5: Writing the Abstract

5.1 Structure

5.2 Grammar and Writing Skills 201

5.2.1 Verb tense 201

5.2.2 Length 204

5.2.3 Language 204

5.3 Writing Task: Build a Model 205

5.3.1 Building a model 205

5.3.2 Key 206

5.3.3 The models 212

5.3.4 Testing the models 213

$\begin{array}{ll}5.4 \text { Vocabulary } & 216\end{array}$

$\begin{array}{ll}\text { 5.4.1 Vocabulary task } & 217\end{array}$

5.4.2 Vocabulary for the Abstract 217

5.5 Writing an Abstract 221

5.5.1 Write an Abstract 221

5.5.2 Key 224

$\begin{array}{ll}5.6 \text { Creating a Title } & 224\end{array}$

$\begin{array}{ll}\text { Sources and Credits } & 229\end{array}$

Useful Resources and Further Reading 231

Appendix A: Abbreviations Used in Science Writing 233

Appendix B: Prefixes Used in Science Writing 234

Appendix C: Latin and Greek Singular and Plural Forms 239

Appendix D: Useful Verbs $\quad 241$

Index of Contents 243

$\begin{array}{ll}\text { Index of Vocabulary } & 245\end{array}$ 